\title{
DEVELOPMENT AND VALIDATION OF RP-HPLC METHOD FOR SIMULTANEOUS QUANTIFICATION OF SULFACETAMIDE SODIUM AND PREDNISOLONE SODIUM PHOSPHATE
}

\author{
NABIHA ABDULLAH ${ }^{1,3}$, FIZZA KARAMAT ${ }^{1 *}$, SHAISTA QAMAR ${ }^{1}$, MATEEN ABBASS $^{2}$, \\ ABDUL MUQEET KHAN ${ }^{2}$ and NASEEM ULLAH ${ }^{3}$ \\ ${ }^{1}$ Institute of Pharmaceutical Sciences (IPS), \\ University of Veterinary and Animal Sciences - UVAS, Lahore, Pakistan \\ ${ }^{2}$ Quality Operation Laboratory (WTO), University of Veterinary and Animal Sciences - UVAS, \\ Lahore, Pakistan \\ ${ }^{3}$ Department of Pharmacy, Quaid-i-Azam University, 45320, Islamabad, Pakistan
}

\begin{abstract}
Sulfacetamide sodium (SFS), in combination with prednisolone sodium phosphate (PSP), is indicated for ophthalmic infections. The present study describes a reverse phase-high performance liquid chromatography method for simultaneous estimation of these two drugs using a diode-array detector. Isocratic elution with solvent system acetate buffer $(0.01 \mathrm{M}, \mathrm{pH} 7)$ : acetonitrile: methanol $75: 20: 5(\mathrm{v} / \mathrm{v} / \mathrm{v})$, at a flow rate of 0.8 $\mathrm{mL} / \mathrm{min}$ gave the optimum resolution. The detection limits for SFS and PSP were calculated as $1.15 \mu \mathrm{g} / \mathrm{mL}$ and $1.45 \mu \mathrm{g} / \mathrm{mL}$, while quantification limits were $3.83 \mu \mathrm{g} / \mathrm{mL}$ and $4.84 \mu \mathrm{g} / \mathrm{mL}$ respectively. Accuracy was found to be $99-101 \%$ with relative standard deviation (RSD) values less than $2 \%$. The proposed method is accurate, precise, sensitive, reproducible and applicable for normal usage in quality control laboratories. It would prove advantageous in utilizing less time and resources as previously there is no reported single assay for simultaneous quantification of the aforementioned drugs.
\end{abstract}

Keywords: sulfacetamide sodium, prednisolone sodium phosphate, reverse phase-high performance liquid chromatography, detection limits, quantification limits

\begin{abstract}
Abbreviations: SFS Sulfacetamide sodium, PSP Prednisolone sodium phosphate, RP-HPLC Reverse phasehigh performance liquid chromatography, DAD Diode array detector, LOD Limit of detection, LOQ Limit of quantification, RSD Relative standard deviation, HPLC-UV High-performance liquid chromatography-ultraviolet visible spectroscopy, UV spectrum Ultraviolet-visible spectrum
\end{abstract}

Sulfacetamide, a principal member of sulfonamide antibiotics, is a bacteriostatic agent. It is a benzenoid amino compound obtained from the parent molecule sulfanilic acid. It is responsible for competitive inhibition of bacterial enzyme dihydropteroate synthetase that causes the synthesis of<smiles>CC(=O)N([NH3+])S(=O)(=O)c1ccc(N)cc1</smiles>

Figure 1. Chemical structure of sulfacetamide sodium para-aminobenzoic acid by fusion of pteridine with aminobenzoic acid, thereby restricting bacterial dihydrofolic acid formation and preventing bacterial cell multiplication (1). It is active against gram positive and gram negative bacteria. It is a potent, white, crystalline, synthetic drug; its sodium salt is used to treat conjunctivitis, blepharitis, trachoma, corneal ulcer and other ophthalmic pathological conditions (2-4). Chemically sulfacetamide sodium (SFS) (Fig. 1) is defined as Sodium acetyl[(4aminophenyl)sulphonyl]azanide having molecular weight $254.2 \mathrm{~g} / \mathrm{mol}(5,6)$. Its ionization constant is 5.4 and biological half-life is 7 to 13 hours (7).

Prednisolone sodium phosphate (PSP) (Fig. 2) is a glucocorticoid, a synthetic corticosteroid used for ocular anti-inflammatory therapy. It acts by

\footnotetext{
* Corresponding author: e-mail: fizza.karamat@uvas.edu.pk
} 


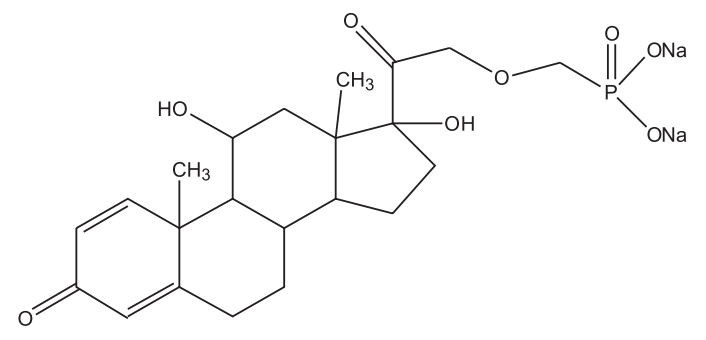

Figure 2. Chemical structure of prednisolone sodium phosphate

inhibiting the production and secretion of cytokines. Chemically, it is defined as [11 $3,17,21$-trihydroxypregna-1,4-dione-3,20-dione-21-(dihydrogen phosphate) disodium salt] (8). It has a molecular weight of $484.4 \mathrm{~g} / \mathrm{mol}(5)$.

Acute infective conjunctivitis is one of the most frequently occurring ophthalmic disorders that accounts for up to $1 \%$ of consultations in primary care. In the United States, an estimated incidence rate of bacterial conjunctivitis is 135 per 10,000 annually i.e. approximately 4 million. It affects both children and adults. It is commonly caused by Haemophilus influenzae, Streptococcus pneumonia, Moraxella catarrhalis and Staphylococcus aureus in infants and older children $(9,10)$. If not diagnosed and treated properly, bacterial conjunctivitis can lead to ocular morbidity of devastating consequences. For this purpose, a variety of antimicrobial agents are being utilized, which when prescribed in combination with corticosteroids become more effective therapeutically as the later further reduce the inflammation of the eye (11). A co-formulation of the aforementioned drugs is available for prophylaxis and treatment of bacterial conjunctivitis and other superficial eye infections. FDA's Center for Drug Evaluation and Research has approved this drug product for its safety and effectiveness (12).

Various analytical techniques have been employed for the quantification of SFS alone or in combination with other pharmaceutical agents. These include UV spectrophotometry $(13,14)$, chromatographic methods including thin layer (TLC) (15), high performance liquid chromatography (HPLC) $(16,17)$, and liquid chromatography-tandem mass spectrometry (LC-MS/MS), capillary electrophoresis (18-20), and dispersive liquid-liquid microextraction (DLLME) method (21). A very few methods have been found in the literature for the estimation of PSP. D. G. Musson along with his coworkers quantified prednisolone sodium phosphate, prednisolone acetate and its primary metabolite, prednisolone by reverse phase HPLC-UV method in aqueous humor of rabbit eyes $(8,22)$. However, extensive literature survey revealed that up till now, a simultaneous method for determination of the drugs under study has neither been reported in pharmaceutical dosage form nor in biological fluids. Therefore, the present study aimed to develop, optimize and validate a method for the simultaneous quantification of SFS and PSP by highly sensitive and modern technique high-performance liquid chromatography using reverse mode of separation and diode array detector (DAD). The method was then applied successfully to the standard binary mixture as well as the commercially available ophthalmic preparation.

\section{EXPERIMENTAL}

The complete study was designed and conducted at Quality Operation Laboratory-An ISO-17025 : 2005 Accredited Lab (WTO), University of Veterinary and Animal Sciences (UVAS), Lahore-Pakistan.

\section{Materials and reagents}

Sulfacetamide sodium (ZAFA Pharmaceutical Laboratories Pvt. Ltd., Pakistan), prednisolone sodium phosphate (Avik Pharmaceutical Ltd., India) and deionized water (Mc Olson Research Laboratories, Pakistan) were kindly gifted. (Sulphapred®) eye drops (5 mL, Ethical labs. Pvt. Ltd., Pakistan) (label claim: sulfacetamide sodium $10 \% \mathrm{w} / \mathrm{v}$, prednisolone sodium phosphate $0.25 \% \mathrm{w} / \mathrm{v}$ ), ammonium acetate (reagent grade, ACS, Scharlau Chemie, Spain), methanol and acetonitrile (HPLC grade, MP Biomedicals, LLC, France) were purchased.

\section{METHOD}

\section{Determination of the $\lambda$ max}

The standard solutions of SFS and PSP having strengths $15 \mu \mathrm{g} / \mathrm{mL}$ were prepared in distilled water. These solutions were scanned by UV Visible Spectrophotometer (UV-1602, BMS, UK) at UV spectrum range 400-200 $\mathrm{nm}$ taking distilled water as a blank. These spectrum scans served to determine the most suitable wavelength at which the drugs showed maximum absorbance. Keeping in view the values of $\lambda$ max of both drugs, the analysis of drugs was carried out at 240,248, and $254 \mathrm{~nm}$ and the optimum wavelength was selected for final analysis.

\section{Chromatographic conditions}

HPLC system consisted of Agilent 1100 series equipped with quat pump G1311A, G1315B diode 
array detector, G1379A degasser, G1313A autosampler, and G1316A column compartment. Promosil C18 $5 \mu \mathrm{m}, 100 \mathrm{~A}^{0}, 4.6 \times 150 \mathrm{~mm}$ column was used (Agela technologies). The chromatographic separation was attained in a reverse phase system by Promosil C18 column $(5 \mu \mathrm{m}, 4.6 \times 150 \mathrm{~mm})$ saturated with an isocratic mobile phase comprising of acetate buffer (0.01 M, pH 7.0): acetonitrile: methanol $75: 20: 5(\mathrm{v} / \mathrm{v} / \mathrm{v})$. The flow rate was kept $0.8 \mathrm{~mL} / \mathrm{min}$; injection volume was $20 \mu \mathrm{L}$. The temperature of the column compartment was maintained at $30^{\circ} \mathrm{C}$ and detection was carried out using a diode array detector (DAD) operated at wavelength 254 $\mathrm{nm}$. Run time of each sample was about 15 minutes. The mobile phase components were filtered before column saturation using $0.45 \mu \mathrm{m}$ nylon filters (diameter $47 \mathrm{~mm}$; Millipore USA).

During the development of the chromatographic procedure, various column types, column configurations, and mobile phase compositions were investigated to ascertain the behavior of the drugs. These include Promosil C18 (5 $\left.\mu \mathrm{m}, 100 \mathrm{~A}^{0}, 4.6 \times 150 \mathrm{~mm}\right)$, Zorbax C8 $(3.5 \mu \mathrm{m}, 4.6 \times 100 \mathrm{~mm})$ and Promosil C18 column $\left(5 \mu \mathrm{m}, 100 \mathrm{~A}^{0}, 4.6 \times 250 \mathrm{~mm}\right)$. Certain mobile phases in varying percentages were tested to acquire highly resolved peaks of the drugs and acceptable retention times. The column was saturated with a mixture of water: acetonitrile in different ratios i.e. $80: 20,85: 15$ and $90: 10(\mathrm{v} / \mathrm{v})$ to achieve an optimum separation with suitable retention times. Buffer strengths, additives and $\mathrm{pH}$ ranges were also investigated to improve resolution (Rs), retention time (tR), peak shape and symmetry of the markers. A mixture comprising of sodium dihydrogen phosphate buffer (0.01 M, pH 5): acetonitrile $60: 40$ $(\mathrm{v} / \mathrm{v})$ was used as mobile phase, furthermore, the $\mathrm{pH}$ of the buffer was altered from 5 to 6.5 to observe the response of the drugs. The mobile phases with different ratios of acetate buffer and acetonitrile were run through the column keeping all other chromatographic parameters constant. First, $0.01 \mathrm{M}$ acetate buffer (pH 7) : acetonitrile $80: 20$ (v/v) was used. Slight variations in the composition of mobile phase i.e. acetate buffer $(0.01 \mathrm{M}, \mathrm{pH} 7)$ : acetonitrile : methanol $75: 15: 10(\mathrm{v} / \mathrm{v} / \mathrm{v}), 80: 15: 5(\mathrm{v} / \mathrm{v} / \mathrm{v})$, $75: 20: 5(\mathrm{v} / \mathrm{v} / \mathrm{v})$ were carried out to obtain better resolution and considerable peak shape. Percentage contents were determined at different $\mathrm{pH}$ values of acetate buffer $(5.5,6.0,7.0,8.0)$ and most suitable $\mathrm{pH}$ was selected for validation studies.

The influence of the temperature of the column compartment and flow rate of mobile phase were also studied. The experiment was conducted at $30^{\circ} \mathrm{C}$ and $40^{\circ} \mathrm{C}$ and optimum temperature and flow rate for quantification of the drugs were determined. The optimum resolution, plate number and most acceptable retention times were achieved with Promosil C18 column $(5 \mu \mathrm{m}, 4.6 \times 150 \mathrm{~mm})$ and acetate buffer $(0.01 \mathrm{M}, \mathrm{pH} 7.0)$ : acetonitrile : methanol $75: 20: 5(\mathrm{v} / \mathrm{v} / \mathrm{v})$ as a mobile phase.

\section{Preparation of standard stock solution}

Standard stock solutions of SFS and PSP were prepared in deionized water, each having concentration of $2000 \mu \mathrm{g} / \mathrm{mL}$ and $400 \mu \mathrm{g} / \mathrm{mL}$ respectively. These solutions were sonicated by using the ultrasonic bath (Supersonic X-3 AFD, model: DSD80A5QS) to achieve efficient mixing. The stock solution of SFS was mixed with that of PSP in $1: 1$ ratio to obtain mix standard stock solution. This solution was vortexed on a vortex mixture (Barnstead International, USA, model: M37610-33) and was used to prepare working standards to perform the validation studies. All the aliquots were filtered prior running through the column by Sartolone polyamide syringe filters $0.2 \mu \mathrm{m}$ (diameter $13 \mathrm{~mm}$, Sartorius Stedim Biotech, Gottingen, Germany).

\section{Preparation of sample solution}

For preparation of sample solution, $0.12 \mathrm{~mL}$ of the commercial preparation was taken and was diluted to $100 \mathrm{~mL}$ with mobile phase.

\section{Method validation}

Once developed, the analytical method is validated to ensure that the analytical procedures and instruments are operating within normal variations providing accurate results (23). Validation provides evidence that the analytical methods adopted for a particular test are suitable for its desired purpose (24). Results of validation parameters assure sensitivity, quality, reliability, and consistency of the developed analytical method. Hence, a systematic approach to method development, optimization and validation is logical and efficient (23). International Conference on Harmonization ( $\mathrm{ICH}$ ) guidelines and the pharmacopeia exhibit the method validation protocols in detail. The current method was validated on the following characteristics:

\section{Linearity}

It is the ability of the analytical procedure to gather the test results that are directly proportional to the concentration of an analyte in the sample. For determination of linearity, serial dilution of the mix standard stock solution with the mobile phase was performed to generate a range of six working standards containing SFS (10, 20, 60, 80, 100, 150 
$\mu \mathrm{g} / \mathrm{mL})$ and PSP $(2.0,4.0,12,16,20,30 \mu \mathrm{g} / \mathrm{mL})$ respectively. The calibration standard solutions were analyzed in triplicate at the given chromatographic conditions. Calibration curves were constructed for both drugs between the corresponding concentrations versus peak areas. All the values were determined by taking the average of three readings. The standard solutions were vortexed and filtered using $0.45 \mu \mathrm{m}$ nylon syringe filters prior injection to the column. Linearity was assessed by visual inspection and determination of correlation coefficient $\left(\mathrm{R}^{2}\right)$.

\section{Recovery, repeatability and reproducibility}

The deviation between the mean value obtained and the actual value is termed as accuracy or recovery (25). The closeness of agreement between a series of observations recorded by performing multifarious sampling of a single homogeneous sample in the prescribed conditions is known as precision. The ICH guidelines reveal that precision should be determined at three diverse levels i.e. repeatability, reproducibility and intermediate precision (23). To calculate recovery, three working standard solutions of the mixture each having concentration of SFS and PSP in the range of standard calibration curves were analyzed in triplicate and quantified from the standard curve. These working solutions were analyzed six times a day in short intervals, and then once on every day for six consecutive days. Their contents were estimated from standard curves to assess interday and intraday precision.

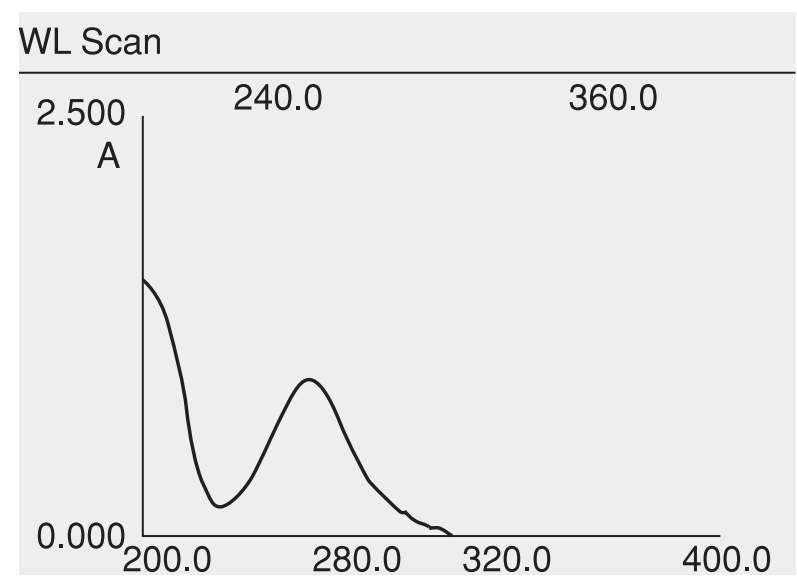

Figure 3. UV spectrum of sulfacetamide sodium in distilled water

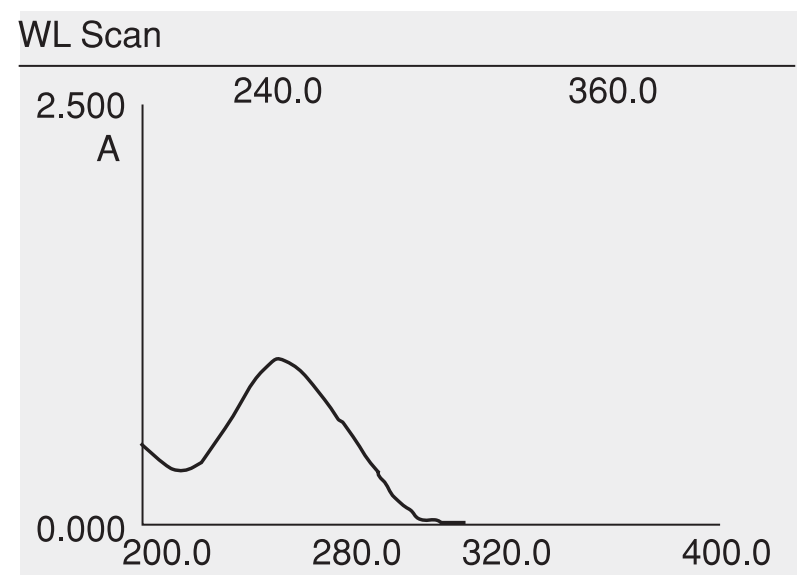

Figure 4. UV spectrum of prednisolone sodium phosphate in distilled water 


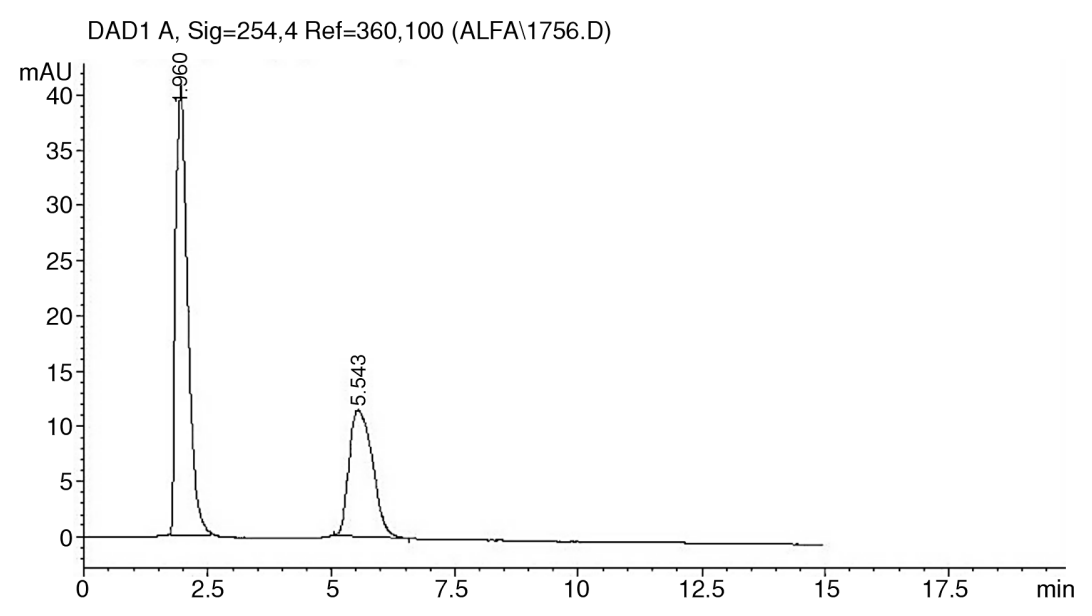

Figure 5. Typical chromatogram of a mixed solution of sulfacetamide sodium and prednisolone sodium phosphate separated by HPLC (retention time $1.960=$ Sulfacetamide sodium, retention time 5.543 = Prednisolone sodium phosphate)

Statistically, accuracy was indicated as a percentage of the drug, while precision was demonstrated as the percent relative standard deviation (RSD).

\section{Sensitivity: limit of detection (LOD) and limit of quantification (LOQ)}

The limit of detection (LOD) is the minimum concentration that gives a response, whereas the quantification limit (LOQ) is the smallest concentration that can be analyzed with accuracy. LOD was calculated at a signal to noise $(\mathrm{S} / \mathrm{N})$ ratio 3 , whereas LOQ was determined at $\mathrm{S} / \mathrm{N}$ ratio 10 (25). Six standard solutions of SFS and PSP mixture in concentration range $10-150 \mu \mathrm{g} / \mathrm{mL}$ and $2.0-30 \mu \mathrm{g} / \mathrm{mL}$ respectively were analyzed by HPLC in five replicates. Calibration curves were constructed between concentration and area of a peak, the linear regression equations were computed and were used to determine LOD and LOQ.

\section{Robustness}

Robustness is defined as the capability of an analytical method to remain unaffected upon minor, deliberate changes in the given procedure's parameters and furnishes with evidence of its reliability and susceptibility during the routine application (25). Small variations in the physical parameters such as wavelength, $\mathrm{pH}$ of buffer solution, mobile phase composition, flow rate, and temperature, were performed and corresponding changes in the obtained chromatogram were recorded. The aliquots analyzed during this whole procedure were from the same mixture.

\section{Specificity}

The specificity of the assay was assessed by quantifying the individual drugs in several binary mixtures of SFS and PSP having the concentration of either drug within its linearity range. The ratio of the drugs in the mixtures was kept similar to that in the commercial preparation.

\section{Application of the method to commercial prepa- ration}

The sample solution and six standard solutions of the mixture were analyzed in triplicate at given chromatographic conditions. The peaks were identified by comparing retention times. The quantification of the drugs was carried out from the respective calibration curves by linear regression equations and the results were compared to that mentioned on the label of the commercial eye preparation.

\section{RESULTS AND DISCUSSION}

In the present era, a number of drugs and their formulations are being introduced increasingly into the market. In parallel, certain chemical and instrumental methods are being developed for analysis of active pharmaceutical ingredients (APIs) present in these dosage forms. One such method of analysis is high-performance liquid chromatography (HPLC). It is a powerful and most widely used technique in analytical chemistry for simultaneous estimation of pharmaceutical agents present in a mixture. The separation of components is acquired by an external pressure that permits small particle size sorbents to 
be used at optimum mobile phase velocities resulting in greater resolution capacity and raised theoretical plate number (26).

With the advent of modern high-pressure liquid chromatography, the conventional column liquid chromatography was virtually displaced from the chemical analysis because the former provided rapid quantification with little manual effort, and though the instrumentation and operating costs were high, the better quality of results and time savings took an edge over those costs. Extremely simple sample preparations and minimum errors associated with HPLC make it a method of choice (27). HPLC can be sub-classified by the mode of separation (reversephase, normal-phase, ion-exchange or ion-pair) and the type of detection (UV absorption, electrochemical, fluorescence, or MS detection) (28). By HPLC, the average detection limits for drugs and related substances are $0.1 \%$ or less and this can be applied in the majority of the circumstances by using conventional UV detectors (29). Reversed-phase mode, when used with UV absorbance detection, provides high resolution, excellent analysis times, reliability, repeatability, sensitivity, and specificity. Due to these characteristics, HPLC is one of the wellknown techniques routinely employed for the quantification of drugs (16).

Sulfacetamide sodium, a bacteriostatic drug when used in conjunction with a glucocorticoid prednisolone sodium phosphate, acts against bacter-

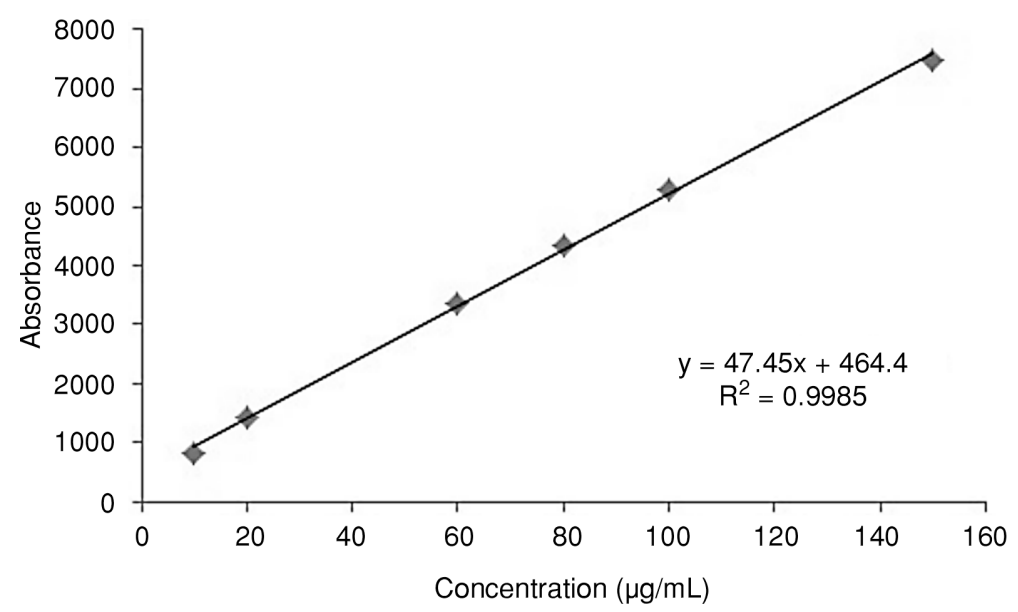

Figure 6. Standard curve of sulfacetamide sodium

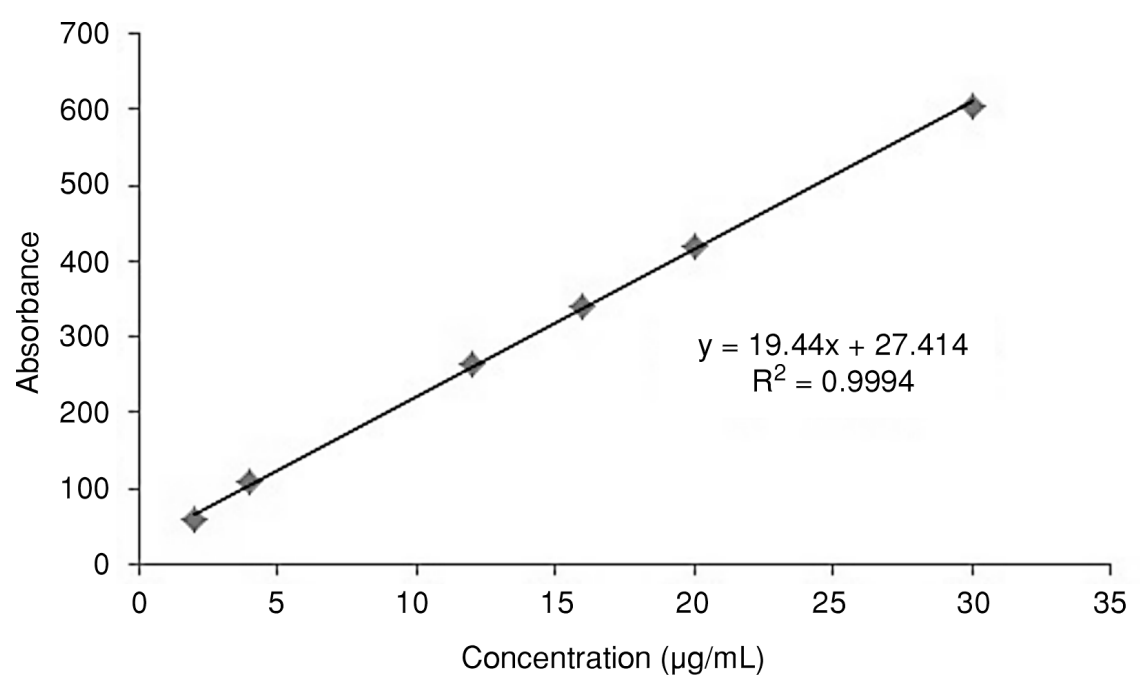

Figure 7. Standard curve of prednisolone sodium phosphate 
Table 1. pH optimization of acetate buffer.

\begin{tabular}{|c|c|c|}
\hline \multirow{2}{*}{ Mobile phase } & \multicolumn{2}{|c|}{ Percentage contents (\%) \pm RSD } \\
\cline { 2 - 3 } & Sulfacetamide sodium & Prednisolone sodium phosphate \\
\hline $\begin{array}{c}\text { Acetate buffer }: \text { acetonitrile : } \\
\text { methanol } 0.01 \mathrm{M}, \mathrm{pH} 5.5 \\
(75: 20: 5)\end{array}$ & $96.28 \pm 1.9$ & $95.91 \pm 2.2$ \\
\hline $\begin{array}{c}\text { Acetate buffer }: \text { acetonitrile : } \\
\text { methanol } 0.01 \mathrm{M}, \mathrm{pH} 6.0 \\
(75: 20: 5)\end{array}$ & $97.76 \pm 1.6$ & $96.5 \pm 3.1$ \\
\hline $\begin{array}{c}\text { Acetate buffer }: \text { acetonitrile : } \\
\text { methanol } 0.01 \mathrm{M}, \mathrm{pH} 7.0 \\
(75: 20: 5)\end{array}$ & $100.27 \pm 1.1$ & $100.47 \pm 1.3$ \\
\hline $\begin{array}{c}\text { Acetate buffer }: \text { acetonitrile : } \\
\text { methanol } 0.01 \mathrm{M} \text {, pH } 8.0 \\
(75: 20: 5)\end{array}$ & $98.56 \pm 2.8$ & \\
\hline
\end{tabular}

Table 2. Calibration data of sulfacetamide sodium and prednisolone sodium phosphate $(n=6)$.

\begin{tabular}{|c|c|c|c|}
\hline \multicolumn{2}{|c|}{ Sulfacetamide sodium } & \multicolumn{2}{c|}{ Prednisolone sodium phosphate } \\
\hline Concentration $(\mu \mathrm{g} / \mathrm{mL})$ & Area of Peak & Concentration $(\mu \mathrm{g} / \mathrm{mL})$ & Area of Peak \\
\hline 10 & 806.93 & 2 & 107.9 \\
\hline 20 & 1424.44 & 4 & 264.16 \\
\hline 60 & 3356.15 & 12 & 351.6 \\
\hline 80 & 4355.3 & 20 & 420.9 \\
\hline 100 & 5310.4 & 30 & 605.12 \\
\hline
\end{tabular}

ial ophthalmic infections. A combined formulation of these two drugs is prescribed in clinical practice. Since the combination is not official in any pharmacopeia, none of the pharmacopeias describes a method for simultaneous quantification of the cited drugs in their combined dosage form. Moreover, to our knowledge, a single assay method capable of quantifying both the given drugs is not available in the literature. The current study describes a new, simple, sensitive, fast and reliable method for the simultaneous assay of SFS and PSP by high-performance liquid chromatography.

For method development, the first objective was to find $\lambda$ max of SFS and PSP separately. Two absorption maxima were found for SFS i.e. $256 \mathrm{~nm}$ and $204 \mathrm{~nm}$. These were comparable to the ones used previously (30). PSP exhibited maximum absorbance at $248 \mathrm{~nm}$ (Figs. 3 and 4). The strongest response was observed at $254 \mathrm{~nm}$; so, it was chosen for final detection and quantification.

During the method development stationary phases of various companies, packing materials and dimensions were examined. Although the separation of the drugs in the mixture was achieved with the mobile phase comprising of water : acetonitrile 80 : $20(\mathrm{v} / \mathrm{v})$, but certainly less retention time (tR) of the peaks suggested making further trials. A solvent mixture consisting of sodium dihydrogen phosphate buffer (0.01 M, pH 5) : acetonitrile $60: 40$ (v/v) was run through the column and the observations revealed that there was a need to further investigate the process to determine a suitable mobile phase. Changes in $\mathrm{pH}$ of buffer did not lead to a satisfactory response of the drugs.

The tR values of SFS and PSP were 1.44 and 9.2 mins respectively with mobile phase $0.01 \mathrm{M}$ acetate buffer ( $\mathrm{pH} 7$ ): acetonitrile: methanol $75: 15$ : $10(\mathrm{v} / \mathrm{v} / \mathrm{v})$. However, the peak shape obtained for PSP was not much satisfactory. A slight variation in the ratio of buffer and methanol i.e. acetate buffer (0.01 M, pH 7): acetonitrile: methanol $80: 15: 5$ $(\mathrm{v} / \mathrm{v} / \mathrm{v})$ resulted in $\mathrm{tR}$ values of 1.45 and $12.30 \mathrm{mins}$ which changed to 1.41 and 4.43 mins for SFS and PSP respectively by a further increase in the ratio of acetonitrile i.e. acetate buffer $(0.01 \mathrm{M}, \mathrm{pH} 7)$ : acetonitrile : methanol $75: 20: 5(\mathrm{v} / \mathrm{v} / \mathrm{v})$. In addition to 
Table 3a. Lowest limit of detection (LOD) and lowest limit of quantification (LOQ) of sulfacetamide sodium.

\begin{tabular}{|c|c|c|c|c|c|}
\hline $\begin{array}{l}\text { Standard } \\
\text { curve }\end{array}$ & $\begin{array}{l}\text { Linear range } \\
(\mu \mathrm{g} / \mathrm{mL})\end{array}$ & Linear regression equation & $\mathrm{R}^{2}$ & Slope & Intercept \\
\hline 1 & $10-150$ & $y=46.27 x+462.29$ & 0.998 & 46.27 & 462.29 \\
\hline 2 & $10-150$ & $y=45.76 x+505.51$ & 0.998 & 45.76 & 505.51 \\
\hline 3 & $10-150$ & $y=47.52 x+461.53$ & 0.998 & 47.52 & 461.53 \\
\hline 4 & $10-150$ & $y=46.728 x+478.38$ & 0.998 & 46.728 & 478.38 \\
\hline 5 & $10-150$ & $y=46.504 x+477.02$ & 0.999 & 46.504 & 477.02 \\
\hline \multicolumn{6}{|c|}{ Mean slope $=46.55$} \\
\hline \multicolumn{6}{|c|}{ Intercept S.D = 17.84} \\
\hline \multicolumn{6}{|c|}{$\mathrm{LOD}=3 \mathrm{SD} / \mathrm{S}=1.15 \mu \mathrm{g} / \mathrm{mL}$} \\
\hline \multicolumn{6}{|c|}{$\mathrm{LOQ}=10 \mathrm{SD} / \mathrm{S}=3.83 \mu \mathrm{g} / \mathrm{mL}$} \\
\hline
\end{tabular}

SD (Standard deviation); S (Mean slope)

Table 3b. Lowest limit of detection (LOD) and lowest limit of quantification (LOQ) of prednisolone sodium phosphate.

\begin{tabular}{|c|c|c|c|c|c|}
\hline $\begin{array}{l}\text { Standard } \\
\text { curve }\end{array}$ & $\begin{array}{l}\text { Linear range } \\
(\mu \mathrm{g} / \mathrm{mL})\end{array}$ & Linear regression equation & $\mathrm{R}^{2}$ & Slope & Intercept \\
\hline 1 & $2.0-30$ & $y=19.812 x+31.369$ & 0.999 & 19.812 & 31.369 \\
\hline 2 & $2.0-30$ & $y=19.076 x+12.963$ & 0.999 & 19.076 & 12.963 \\
\hline 3 & $2.0-30$ & $y=19.25 x+25.038$ & 0.999 & 19.25 & 25.038 \\
\hline 4 & $2.0-30$ & $y=19.076 x+14.463$ & 0.998 & 19.076 & 14.463 \\
\hline 5 & $2.0-30$ & $y=19.197 x+33.046$ & 0.998 & 19.197 & 33.046 \\
\hline \multicolumn{6}{|c|}{ Mean slope $=19.28$} \\
\hline \multicolumn{6}{|c|}{ Intercept S.D $=9.33$} \\
\hline \multicolumn{6}{|c|}{$\mathrm{LOD}=3 \mathrm{SD} / \mathrm{S}=1.45 \mu \mathrm{g} / \mathrm{mL}$} \\
\hline \multicolumn{6}{|c|}{$\mathrm{LOQ}=10 \mathrm{SD} / \mathrm{S}=4.84 \mu \mathrm{g} / \mathrm{mL}$} \\
\hline
\end{tabular}

SD (Standard deviation); S (Mean slope)

Table 4. System suitability parameters.

\begin{tabular}{|c|c|c|c|c|}
\hline Drug name & Retention time & Theoretical plates & Resolution & Peak shape \\
\hline Sulfacetamide sodium & 1.960 & 4504 & 2 & ++ \\
\hline Prednisolone sodium phosphate & 5.543 & 6173 & 2.9 & ++ \\
\hline
\end{tabular}

Chromatographic conditions: mobile phase acetate buffer (0.01 M, pH 7): acetonitrile: methanol $75: 20: 5$ (v/v/v), column C18 (4.6 $\times 150$ $\mathrm{mm}$ ), flow rate $0.8 \mathrm{~mL} / \mathrm{min}$, injection volume $20 \mu \mathrm{L}$, temperature $30 \mathrm{oC}$, wavelength $254 \mathrm{~nm},++$ means acceptable peak shape

Table 5a. Intraday and interday accuracy and precision of assay of sulfacetamide sodium $(\mathrm{n}=6)$.

\begin{tabular}{|c|c|c|c|c|}
\hline \multirow{2}{*}{$\begin{array}{c}\text { Concentration } \\
(\mu \mathrm{g} / \mathrm{mL})\end{array}$} & \multicolumn{2}{|c|}{ Intra day assay } & \multicolumn{2}{c|}{ Inter day assay } \\
\cline { 2 - 5 } & Accuracy $\pm \mathrm{SD}$ & Precision RSD & Accuracy \pm SD & Precision RSD \\
\hline 20 & $101.72 \pm 0.638$ & 0.032 & $100.17 \pm 0.909$ & 0.045 \\
\hline 80 & $100.76 \pm 0.833$ & 0.010 & $100.43 \pm 0.535$ & 0.007 \\
\hline 150 & $99.01 \pm 0.866$ & 0.006 & $99.36 \pm 0.653$ & 0.004 \\
\hline
\end{tabular}

SD (Standard deviation) 
Table 5b. Intraday and interday accuracy and precision of assay of prednisolone sodium phosphate $(n=6)$.

\begin{tabular}{|c|c|c|c|c|}
\hline \multirow{2}{*}{$\begin{array}{c}\text { Concentration } \\
(\mu \mathrm{g} / \mathrm{mL})\end{array}$} & \multicolumn{2}{|c|}{ Intra day assay } & \multicolumn{2}{c|}{ Inter day assay } \\
\cline { 2 - 5 } & Accuracy $\pm \mathrm{SD}$ & Precision RSD & Accuracy $\pm \mathrm{SD}$ & Precision RSD \\
\hline 4.0 & $100.66 \pm 0.076$ & 0.019 & $100.54 \pm 0.077$ & 0.019 \\
\hline 16 & $100.01 \pm 0.249$ & 0.016 & $100.00 \pm 0.198$ & 0.012 \\
\hline 30 & $99.68 \pm 0.149$ & 0.005 & $99.65 \pm 0.226$ & 0.008 \\
\hline
\end{tabular}

SD (Standard deviation)

Table 6. Percentage contents of sulfacetamide sodium and prednisolone sodium phosphate $(n=3)$.

\begin{tabular}{|c|c|c|}
\hline $\begin{array}{c}\text { Commercial preparation } \\
\text { name }\end{array}$ & $\begin{array}{c}\text { Active pharmaceutical } \\
\text { ingredient (API) }\end{array}$ & $\begin{array}{c}\text { Percentage contents } \\
(\%)\end{array}$ \\
\hline \multirow{2}{*}{ Sulphapred eye drops } & Sulfacetamide sodium & 100.27 \\
\cline { 2 - 3 } & Prednisolone sodium phosphate & 100.47 \\
\hline
\end{tabular}

this, a well-resolved peak for PSP was obtained in comparison to all the above mentioned mobile phase ratios. It was observed that an increase in the concentration of acetonitrile in the mobile phase resulted in a decrease in the retention times of the drugs. This behavior has previously been described by Gallego and Arroyo (11).

Furthermore, the experiment was performed at acidic, basic and neutral $\mathrm{pH}$ of acetate buffer solution in order to optimize its $\mathrm{pH}$. The best results were obtained at $\mathrm{pH} 7$ (Table 1). Changes in retention time were observed by altering the flow rate. As the flow rate was reduced to $0.8 \mathrm{~mL} / \mathrm{min}$ from $1 \mathrm{~mL} / \mathrm{min}$, the retention time shifted from 1.41 and 4.43 to 1.96 and 5.54 for SFS and PSP respectively. From this, we concluded that a decrease in the flow rate of the mobile phase results in an increase in retention time of the entities, as reported earlier (11). The peaks obtained for both the drugs were sharp and had clear baseline separation. Therefore, a flow rate of 0.8 $\mathrm{mL} / \mathrm{min}$, Promosil C18 column of $150 \mathrm{~mm}$, a mobile phase of acetate buffer $(0.01 \mathrm{M}, \mathrm{pH} 7)$ : acetonitrile : methanol $75: 20: 5(\mathrm{v} / \mathrm{v} / \mathrm{v})$, and a temperature of $30^{\circ} \mathrm{C}$ were selected as a compromise between analysis time, peak symmetry, theoretical plate number, and peak resolution (Fig. 5). The retention time values were then compared with the values of previously reported retention times for SFS, and it was found that the tR of the former was reduced to $1.96 \mathrm{mins}$ from 7.3 (31) and 4.9 mins (32). Since recent literature does not report an assay for determination of PSP in solvent by RP-HPLC-DAD; hence, the current method has the advantage of lesser retention time values and short analysis time for both drugs.
The linearity of the method was assessed by analyzing a series of standard solution of concentration range $10-150 \mu \mathrm{g} / \mathrm{mL}$ for SFS and 2-30 $\mu \mathrm{g} / \mathrm{mL}$ for PSP. The calibration curves plotted between concentration and area under the peak showed linear response in the given concentration range with correlation coefficient values 0.9985 and 0.9994 and the linear regression equations $(y=47.45 x+464.4)$ and $(y=19.44 x+27.414)$ for SFS and PSP respectively, as shown in (Figs. 6 and 7) and (Table 2).

Sensitivity of the method was measured by statistical calculation of limit of detection (LOD) and limit of quantification (LOQ) of both drugs. LOD and LOQ values for SFS and PSP were $1.15 \mu \mathrm{g} / \mathrm{mL}$ and $1.45 \mu \mathrm{g} / \mathrm{mL}$, and $3.83 \mu \mathrm{g} / \mathrm{mL}$ and $4.84 \mu \mathrm{g} / \mathrm{mL}$ respectively. These values indicate that both drugs can be easily detected and estimated in a mixture (Table $3 \mathrm{a}$ and $3 \mathrm{~b}$ ).

The changes in the chromatographic results of the system suitability were monitored by altering some physical parameters, such as $\mathrm{pH}( \pm 0.2$ units), column temperature $\left( \pm 2^{\circ} \mathrm{C}\right)$, flow rate $( \pm 2 \%)$ and wavelength $( \pm 2 \mathrm{~nm})$. No variations in selectivity, symmetry, peak width and peak resolution were noticed which proved that the developed method was robust. System suitability parameters are given in (Table 4).

The results obtained from six standard samples were used to calculate relative standard deviation (RSD) which came out to be less than $2 \%$ for both drugs. The results of recovery, intraday and interday accuracy and precision values of the method are given in (Table 5a and 5b). Mean recovery values were found in accordance with the limits defined by British Pharmacopoeia (BP) 2015 (6). 
The developed method was then applied to the commercially available preparation containing a mixture of drugs under study. The chromatograms obtained after triplicate analysis of the sample mixture presented similar peaks and retention times as that of standard solution. Mean recovery values are given in (Table 6). The results of the percentage contents calculated in comparison to the label claim indicated that the proposed HPLC method was sensitive, specific, reproducible, and reliable for simultaneous quantification of SFS and PSP.

\section{CONCLUSION AND FUTURE PERSPECTIVES}

To our literature survey, this is the first account for the development, optimization, and validation of an RP-HPLC method for simultaneous detection and quantification of SFS and PSP in a mixture. The proposed analytical method proved sensitive, accurate, robust, precise, easy and economical. The method was applied successfully for estimation of the cited drugs in the combined dosage form and the results obtained were in great accordance with the label claim. In conclusion, the method can be applied for the assay analysis of the aforementioned drugs individually as well as in a binary mixture and can be used for the routine procedures of quality control. In the future, stability indicating assay analysis can be established for the same combination of drugs in solvent and biological fluids.

\section{Competing interests}

\section{None}

\section{Acknowledgment}

We have deep gratitude for Dr. Farzana Chowdhary, Director, Institute of Pharmaceutical Sciences, University of Veterinary and Animal Sciences, Lahore, for enlightening us and providing us with all possible facilities for completion of this research work.

\section{REFERENCES}

1. Yadav S.K., Choubey P.K., Agrawal B., Goyal R.N.: Talanta 118, 96 (2014).

2. Sensoy D., Cevher E., Sarıcı A., Yılmaz M., Özdamar A., Bergişadi N.: Eur. J. Pharm. Biopharm. 72, 487 (2009).

3. Sridhar M.S., Sharma S., Reddy M.K., Mruthyunjay P., Rao G.N.: Cornea 17, 17 (1998).
4. Colomina J., Esparza L., Buesa J., Mari J.: Med. Clin-Barcelona 108, 424 (1997).

5. Bayer G.: Martindale: the complete drug reference, $39^{\text {th }}$ edn., Alison B, Australian prescriber, Australia 2015.

6. Pharmacopoeia B. British pharmacopoeia 2016.

7. Mandal B., Alexander K.S., Riga A.T.: J. Pharm. Pharm. Sci. 13, 510 (2010).

8. Musson D.G., Bidgood A.M., Olejnik O.: J. Chromatogr. B 565, 89 (1991).

9. Smith A.F., Waycaster C.: BMC Ophthalmol. 9, 13 (2009).

10. Sheikh A., Hurwitz B.: Cochrane Database Syst. Rev. 2 (2006).

11. Gallego J.L., Arroyo J.P.: J. Pharmaceut. Biomed. 30, 1255 (2002).

12. Home F.: Orange book: approved drug products with therapeutic equivalence evaluations. USA: US Food \& Drug Administration 2013.

13. Errayess S.A., Lahcen A.A., Idrissi L., Marcoaldi C., Chiavarini S., Amine A.: Spectrochim. Acta A 181, 276 (2017).

14. Nagaraja P., Naik S., Shrestha A., Shivakumar A.: Acta Pharm. 57, 333 (2007).

15. Choma I., Jesionek W.: Thin layer chromatography in drug analysis $1^{\text {st }}$ edn., Lukasz K., Monika W-H., Joseph S. Eds., Taylor and Francis, CRC Press, Newyork 2013.

16. Sajid M., Na N., Safdar M., Lu X., Ma L., He L. et al.: J. Chromatogr. A 1314, 173 (2013).

17. Lin C-Y., Huang S-D.: Anal. Chim. Acta. 612, 37 (2008).

18. Injac R., Kočevar N., Štrukelj B.: Croat. Chem. Acta 82, 685 (2009).

19. Jamal S., Baderia V.K., Agrawal Y., Sanghi S.: Arab. J. Chem. (2014).

20. Wang A., Gong F., Li H., Fang Y.: Anal. Chim. Acta 386, 265 (1999).

21. Herrera-Herrera A.V., Hernández-Borges J., Afonso M.M., Palenzuela J.A., RodríguezDelgado M.Á.: Talanta 116, 695 (2013).

22. Musson D., Bidgood A., Olejnik O.: J. Ocul. Pharmacol. Ther. 7, 175 (1991).

23. Shabir G.A.: J. Chromatogr. A 987, 57 (2003).

24. Gumustas M., Ozkan S.A.: Open Anal. Chem. J. 5, 1 (2011).

25. International Conference on Harmonization Guidelines, Validation of analytical procedures, Proceeding of the International Conference on Harmonisation (ICH), Commission of the European Communities, Geneva 2005.

26. Thompson M., Ellison S.L., Wood R., Thompson M., Ellison S.L.: Pure Appl. Chem. 74, 835 (2002). 
27. Rao R.N., Nagaraju V.: J. Pharmaceut. Biomed. 33, 335 (2003).

28. Stead D.A.: J. Chromatogr. B 747, 69 (2000).

29. Gilpin R., Pachla L.: Anal. Chem. 71, 217 (1999).

30. Hartig C., Storm T., Jekel M.: J. Chromatogr. A. 864, 163 (1999).
31. Rao R., Rao Y., Shah A.: J. Pharmaceut. Biomed. 20, 717 (1999).

32. Garcia-Alvarez-Coque M., Simo-Alfonso E., Ramis-Ramos G., Esteve-Romero J.: J. Pharmaceut. Biomed. 13, 237 (1995).

Received: 14.04. 2018 